\title{
Professor Masaki Kitajima (1941-2019): An Unparalleled International Surgeon Diplomat
}

\author{
Michael Sarr ${ }^{1}$
}

Published online: 24 September 2019

(C) Société Internationale de Chirurgie 2019

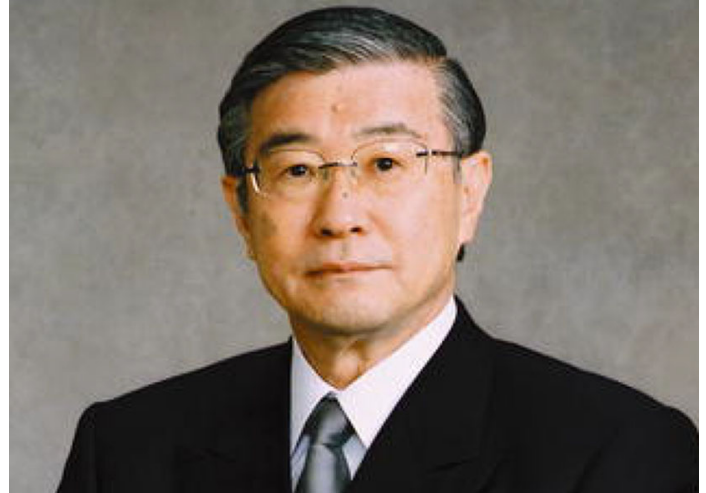

On May 21, 2019, our noble International House of Surgery lost a truly remarkable man-Professor Masaki Kitajima from Japan. Professor Kitajima was short of stature (by height) but a giant by his quiet but palpable presence, huge yet unassuming personality, and possibly most importantly, his continued belief in and unrelenting support of the younger generation. Everyone who knew him will say he always had a quiet smile accompanied by his personal interest in everyone. His wonderful, dignified wife fully complimented him as well.

Professor Kitajima achieved all the highest positions in surgery in Japan. He was the president of numerous academic and clinical societies, organized numerous surgical meetings, authored over 1000 articles and multiple books, and to further show his international reputation, was a member of the editorial board of the New England Journal of Medicine-yes he did all of these, but despite these numerous academic accolades, his legacy is that of an International Diplomat in Surgery who won the respect of everyone he met because of his mutual respect, insight, and unparalleled demeanor. Within this realm, he trained 20 professors of surgery in Japan, and equally important, encouraged and supported many, many young surgeons from Japan, but also supported other young surgeons from outside countries as well and encouraged them to be their best (as he did with me the first time I met him the early 1990s). Unlike many distinguished professors, he always had time for anyone who sought his insight and wisdom on a multitude of questions/concerns.

As many readers of this Memorial will know, Professor Kitajima was the President of the International Society of Surgery (ISS) from 2005 to 2007 , but one thing he always remembered and held to be a true honor for him was to give the Grey Turner Lecture in Brussels in the ISS-SIC meeting in 2001 titled "Progress in GI cancer management: challenges in the 21st Century," such a perfect, fitting choice for the ISS (celebrating the upcoming 100th anniversary of former ISW/current ISS-SIC) and such an appropriate title for him . All of us will remember and celebrate his life for all he has done for ALL OF US in the International House of Surgery.

Publisher's Note Springer Nature remains neutral with regard to jurisdictional claims in published maps and institutional affiliations.

Michael Sarr

sarr.michael@mayo.edu

1 Rochester, USA 